\title{
Análise da implantação de políticas públicas na aldeia Limão Verde, em Aquidauana-MS: uma contribuição para a implementação de propostas de etnodesenvolvimento The analysis of the implantation of public politics in the Limão Verde village, in Aquidauana-MS: a contribution to the implementation of proposals of ethnodevelopment
}

Simone Rodrigues

Resumo: O presente artigo analisa os impactos causados pela implantação de projetos governamentais de fomento agropecuário, geração de renda e desenvolvimento local na aldeia Limão Verde, em AquidauanaMS. A pesquisa busca investigar até que ponto os programas de apoio à produção têm caráter benéfico e aportam contribuições para o desenvolvimento socioeconômico dessa população. Para a realização do estudo foram analisados os Programas Pantanal, Tupã I e Segurança Alimentar e realizadas inúmeras entrevistas com indígenas de Limão Verde. O estudo permitiu demonstrar a capacidade de os indígenas gerirem os projetos implantados e também a sua não dependência em relação aos programas governamentais confirmada pela constatação da continuidade da produção agrícola na aldeia, no período analisado. Permitiu constatar, ainda, a importância da atuação efetiva dos agentes governamentais, concluindo que o "etnodesenvolvimento" pretendido depende do comprometimento do poder público com essa sociedade.

Palavras-chave: Terena; políticas públicas; desenvolvimento local.

Abstract The article in hand analyses the impacts caused by the implantation of governmental projects of agricultural development, generation of income and local development in the Limão Verde village, in Aquidauana/MS. The research seeks to investigate up to what point the programs of support for production have a beneficial character and bring contributions for the social-economical development of this

Zootecnista. Mestre em G eografia pela UFMS. Gestora de Desenvolvimento Rural - AG RAER. simonecpereira@ hotmail.com 
population. For the carrying out of the study, the Pantanal Programs, Tupi I and Food Security, were analysed and inumerous interviews with indigenous people from Limão Verde were carried out. The study permitted demonstrating the capacity of the indigenous people to administer the projects implanted and, also, their nondependence in relation to the governmental programs, confirmed by the verification of the continuity of agricultural production in the village during the period analysed. It also permitted verifying the importance of the effective action of governmental agents, concluding that the "ethnodevelopment" intended depends on the responsibility of public power with this society.

Key words: Terena; public politics; local development.

\section{Introdução}

O presente artigo versa sobre os impactos sócio-econômicos decorrentes da implementação de Políticas Públicas na aldeia indígena Limão Verde, localizada no município de Aquidauana-MS. A motivação para a pesquisa remonta ao ano de 2002, quando a então pesquisadora, no papel de agente governamental, participou da execução de programas para o desenvolvimento das sociedades indígenas baseados nas questões de etnodesenvolvimento e desenvolvimento local. Assim, com o desenrolar dos trabalhos nas aldeias, a pesquisadora se deparou com experiências que proporcionaram uma análise da realidade indígena, ampliando a percepção em relação às lacunas e aos exaustivos insucessos ocasionados durante o desenvolvimento das ações dos programas implantados. Dessa forma, diversos questionamentos surgiram quanto ao papel do Estado no desenvolvimento desses povos, sobre a necessidade de identificar contribuições e/ou danos impactantes ocorridos e de que forma os indígenas avaliavam tais ações.

O etnodesenvolvimento, proposto em discursos técnicos e políticos, vem atingindo crescentes dimensões, presumindo uma política de superação dos problemas sociais, econômicos e ambientais e a satisfação das necessidades básicas das comunidades indígenas, respeitando características próprias desses povos. Para compreender um pouco da trajetória das políticas públicas e seus impactos na aldeia Limão Verde, este artigo apresenta alguns resultados do estudo de três programas implantados: o Programa Pantanal, o Programa Tupã I e o Segurança Alimentar. Ressalta alguns problemas que ocasionam muitos fracassos na implantação de projetos e programas de iniciativa pública, além de tecer reflexões acerca do planejamento do Estado e da atuação dos agentes públicos no intuito de satisfazer as aspirações indígenas.

186 Simone Rodrigues Pereira CO RRÊA. Análise da implantação de políticas... 


\section{A aldeia Limão Verde}

Para que se realize o estudo dos resultados gerados pelo contato com indivíduos externos dentro da aldeia Limão Verde e avaliar impactos com a implantação de políticas públicas para o desenvolvimento local, faz-se necessário entender como se desenvolvem os processos de relações econômicas, políticas, sociais, culturais e a relação com o meio ambiente por parte desses povos.

Os Terena fazem parte da identidade do Estado de Mato Grosso do Sul, tanto por seu contingente populacional, quanto por sua importância histórica e cultural. Sua etnohistória tem sido pesquisada e descrita há muito tempo, desde os primeiros contatos com os colonizadores.

Os Terena, um dos subgrupos Guaná que, como outros povos, pertencem ao grupo lingüístico Aruak, contribuíram para a formação do sudoeste brasileiro como produtores de alimentos e outros bens materiais - algodão, couro, palha - para o consumo dos primeiros moradores portugueses e brasileiros em troca de ferramentas e gado, servindo também como mãode-obra nas fazendas e, após a Guerra do Paraguai, na construção de linhas telegráficas da região, além, da Estrada de Ferro Noroeste do Brasil.

O município de Aquidauana possui três Terras Indígenas - terras reservadas para usufruto dos índios terena, pelo Serviço de Proteção aos Índios, SPI -, cada uma com um Posto Indígena (PIN): Taunay, Ipegue e Limão Verde. São nove aldeias nessas três terras indígenas: cinco em Taunay, duas em Ipegue e duas em Limão Verde, todas de etnia Terena, com uma população aproximada de 1382 famílias (FUNASA, 2007).

A Terra Indígena Limão Verde que foi criada como tal, em $1972^{1}$, é composta pelas aldeias Limão Verde e Córrego Seco. O PIN encontra-se na aldeia Limão Verde, ligado à Administração Executiva Regional de Campo Grande (MS). Localiza-se a $23 \mathrm{Km}$ da sede do município de Aquidauana, possuindo uma área de aproximadamente 4.086 hectares (Fehlauer, 2004), na qual vivem cerca de 1094 indígenas (301 famílias e 233 residências), segundo a FUNASA (2007).

Na organização social Terena existe uma divisão de atividades de acordo com o sexo. Os homens são conhecidos por serem essencialmente agricultores. Além do trabalho na roça, os Terena da aldeia Limão Verde saem para trabalhar como peões em fazendas, em usinas de cana-deaçúcar e em serviços temporários, como: capinas, colheita de cereais, instalação de cercas, etc. A "changa", como denominam essa prestação temporária de serviços fora de suas terras, é caracterizada por serviços 
gerais como carga e descarga de caminhão, entre outros, encontrados pelos indígenas nas cidades.

Um dos pontos responsáveis pelo processo de interação dos Terena com a sociedade não indígena é a sua participação na economia regional. Embora o trabalho na agricultura seja atribuição principal dos homens, as mulheres também exercem importante e significativo papel nas relações socioeconômicas, pois são as principais responsáveis pelo escoamento dos produtos de agricultura e artesanato da aldeia, por meio da comercialização. São elas que realizam a venda dessa produção nos mercados regionais. Atuam, portanto, ativamente, juntamente com os homens, nas atividades econômicas da comunidade.

Observa-se que, dentro da aldeia Limão Verde, a comunicação é realizada por meio do idioma terena, especialmente, entre os moradores mais velhos. E, também, por meio do português, preferido pelos jovens. O domínio da língua portuguesa foi adquirido, historicamente, segundo os indígenas, em decorrência do intenso contato com a sociedade não indígena (que, em determinados momentos históricos, proibía aos indígenas o uso da sua língua materna, o terena).

As unidades de produção da aldeia pertencem aos grupos domésticos formados, principalmente, por irmãos, sob a orientação do pai, passando de uma geração a outra. Cada indivíduo trabalha a sua unidade, porém, quando necessário, trabalham em sistema de "mutirão". Segundo a pesquisa, metade $(50 \%)$ das unidades de produção tem a extensão de 1 (um) hectare.

A criação da Terra Indígena promoveu o uso de tecnologia convencional para o aumento da produtividade e geração de renda por meio de comercialização do excedente. Com isso, foram modificadas as formas de cultivo, passando de itinerantes para áreas fixas, de uso contínuo e intensivo, por meio da incorporação de tratores agrícolas. Conseqüentemente, junto com o aumento da produção agrícola, houve a queda do uso de técnicas tradicionais e de sementes nativas. Segundo Brand (2001, p. 67), são "relevantes os processos de mudança cultural em curso, as transformações resultantes do impacto com o entorno e a visão de mundo que norteia estes povos no limiar do novo milênio".

Outro ponto a ser ressaltado nesse contexto de diminuição do uso de técnicas agrícolas tradicionais é a necessidade constante de insumos, como sementes e óleo diesel para o funcionamento dos tratores.

A agricultura continua sendo a principal fonte de subsistência e renda, todavia, segundo os Terena, está cada vez mais difícil suprir as

188 Simone Rodrigues Pereira CO RRÊA. Análise da implantação de políticas... 
necessidades básicas das famílias. A comercialização dos produtos das unidades de produção indígena para constituir a renda familiar vem sendo reduzida, de acordo com os Terena aldeados. Isso devido ao empobrecimento do solo, ao crescimento das famílias e conseqüente divisão de áreas de roça que ocasionam a diminuição das unidades de produção por família, além da impossibilidade de se obter novas áreas para plantio e de se recuperar as áreas "enfraquecidas".

Com o enfraquecimento do solo, as espécies vegetais mais exigentes não são mais produzidas, diminuindo significativamente a diversidade das culturas, o que gera um grande problema a esses agricultores natos, acostumados com o plantio de várias espécies diferentes, cada qual em sua época, permitindo plantios e colheitas durante o ano inteiro.

Os moradores dessa aldeia participam ativamente do processo político interno - organização social participativa - e externo. Participação essa conquistada por sua índole pacífica que permitiu serem tratados, apesar do preconceito, como cidadãos. É importante observar a dimensão que vem tomando o número de organizações indígenas, principalmente associações, trazendo reivindicações e buscando espaços na sociedade ocidental.

O novo formato ou crescimento representativo dessas organizações se deve principalmente, de acordo com os próprios indígenas, à parte do processo necessário para o alcance de benefícios, que são conseguidos apenas através de organizações formais dentro da aldeia, bem como por exigência dos poderes públicos ou organizações não-governamentais.

Além da existência dessas organizações dentro da aldeia existem outras lideranças como o chefe de posto da FUNAI e o cacique. O cacique é considerado autoridade máxima dentro da aldeia e possui o papel de articular e garantir a execução das leis, ou do regimento interno que rege o funcionamento do trabalho interno da comunidade. O chefe do PIN realiza principalmente trabalhos administrativos, como expedição de documentos oficiais.

Apesar da particularidade na organização interna da Limão Verde, o entorno influencia essa organização, estimulando divisões político partidárias que criam, muitas vezes, problemas entre as lideranças e são acentuados, principalmente em épocas de eleição, quando o acesso às aldeias por candidatos de diversos partidos é livre.

Outro ponto de destaque constatado refere-se à mudança em relação à religiosidade. Na antiga sociedade Terena existia a figura dos Pajés 
que exerciam o papel de rezadores ou curandeiros. Hoje existe, segundo os índios, apenas um rezador na aldeia, que não é mais denominado de pajé. É o último, segundo os indígenas, pois ninguém se interessa em dar continuidade ao seu trabalho.

Existe apenas uma Igreja Católica denominada de Santo Afonso, que foi construída em 1932, pela mão-de-obra indígena. Os indígenas destacaram a atuação dos padres redentoristas e das irmãs vicentinas na conversão dos indígenas em cristãos por meio de batismo, de casamentos, entre outras práticas. As Igrejas Protestantes também se instalaram na aldeia, ocasionando conflitos com a Igreja Católica e contribuindo também para novas divisões internas dentro da aldeia. Existem hoje seis igrejas protestantes na aldeia: UNIEDAS; Assembléia de Deus-Missões; Deus é Amor; Missionária Jerusalém Avivamento; Batista Indígena e Batista do Limão Verde.

A aldeia é dotada de infra-estrutura básica. Apesar do quadro apresentado de uma comunidade organizada e dinâmica, de um povo que procura alternativas para sua sobrevivência física e cultural, os Terena ainda sofrem o preconceito da sociedade envolvente.

\section{O etnodesenvolvimento como base conceitual das políticas públicas indigenistas}

Nos últimos anos, principalmente no início deste século, para contextualizar os discursos tanto dos órgãos governamentais quanto não governamentais ${ }^{2}$, utilizam-se com maior freqüência os termos etnodesenvolvimento, desenvolvimento participativo e desenvolvimento local, que, segundo Verdum (2005, p. 9), "têm servido como senha de articulação e convergência das ações de inúmeras pessoas e instituições".

Nesse contexto, o etnodesenvolvimento, de acordo com Stavenhagen (1984, p. 57, apud Azanha, 2002, p. 31):

[...] significa que uma etnia, autóctone, tribal ou outra, detém o controle sobre suas próprias terras, seus recursos, sua organização social e sua cultura, e é livre para negociar com o Estado o estabelecimento de relações segundo seus interesses.

Os discursos dos órgãos governamentais acentuam que as metas da política de desenvolvimento, incluindo a proteção do meio ambiente, devem visar igualmente o bem-estar da sociedade indígena. Questionase, porém, de quem seria, realmente, este propagado bem-estar, uma vez que o desenvolvimento socioeconômico nem de longe beneficia a grande

190 Simone Rodrigues Pereira CO RRÊA. Análise da implantação de políticas... 
maioria da população. $\mathrm{O}$ que dizer, então, de comunidades diferenciadas como as indígenas? E ainda mais, como promover a preservação do meio ambiente, em comunidades como as terena, que sobrevivem da exploração dos recursos naturais de seus limitados territórios? Efetivamente, os relatórios e acordos internacionais, em sua grande maioria, não incluem de fato esses povos no planejamento do desenvolvimento mundial, pois, tanto o Terena quanto outros povos nem sempre participam ou são consultados sobre as suas aspirações ao desenvolvimento.

O importante, porém, é que diferentemente das perspectivas de desenvolvimento no formato convencional, o etnodesenvolvimento ${ }^{3}$ se propõe a estabelecer relações mais eqüitativas entre "índios" e "brancos", promovendo o intercâmbio de conhecimentos e buscando, sobretudo, pensar formas de relacionamento menos assimétricas.

O desenvolvimento convencional apóia-se, especialmente, em indicadores econômicos, enquanto o etnodesenvolvimento, como base conceitual das políticas públicas do Estado em relação às sociedades indígenas nacionais, apóia-se, segundo Azanha (2002, p. 32), em outros indicadores ou metas, tais como:

[...] a) aumento populacional, com segurança alimentar plenamente atingida; b) aumento do nível de escolaridade, na "língua" ou no português, dos jovens aldeados; c) procura pelos bens dos "brancos" plenamente satisfeita por meio de recursos próprios gerados internamente de forma não predatória, com relativa independência das determinações externas de mercado na captação de recursos financeiros; e d) pleno domínio das relações com o Estado e agências de governo, a ponto de a sociedade indígena definir essas relações, impondo o modo como deverão ser estabelecidas.

Porém, para atingir essas metas necessárias na execução de projetos, Azanha (2002, p. 32) ressalta alguns pressupostos:

a) segurança territorial, satisfazendo plenamente as necessidades de expansão da sociedade indígena; b) usufruto exclusivo dos recursos naturais; c) demanda por produtos manufaturados e meios para consegui-los: d) tempo empregado na geração de recursos financeiros internos para a aquisição de produtos manufaturados; e) escala ou nível das necessidades impostas pelo contato e identificação de como cada sociedade indígena específica fixa ou fixou esse nível; e f) internacionalização dos recursos financeiros gerados pelos canais tradicionais de distribuição e circulação.

As propostas atuais dos vários projetos de desenvolvimento previstos para as terras indígenas Terena objetivam, principalmente, o fomento do etnodesenvolvimento. Contudo, é necessário um suporte técnico e 
político, tendo em vista a diversidade desses povos, de maneira que eles possam se desenvolver com autonomia diante do posicionamento que a sociedade não indígena apresenta em relação a eles.

Fica bastante claro que o Estado, apesar dos discursos sobre a importância e a necessidade da gestão participativa dos programas a serem desenvolvidos nas aldeias indígenas, ainda está distante do que realmente se considera um etnodesenvolvimento. Falta aos agentes governamentais, além do comprometimento político, conhecimento, principalmente, de como essas comunidades se organizam. De outra parte, pode não ser do interesse do Estado a implantação de programas efetivos de etnodesenvolvimento nas terras indígenas, visto que esses programas podem provocar uma redefinição do modo como as comunidades indígenas orientam suas relações com o Estado, assumindo a real gestão do seu desenvolvimento socioeconômico.

\section{Principais aspirações indígenas como base para a elaboração de políticas públicas}

Em 2002, instituiu-se a Comissão Intersetorial de Saúde, integrante do Conselho Nacional de Saúde ${ }^{4}$, com a participação de organizações indígenas, para formular políticas públicas baseadas em um diagnóstico sobre segurança alimentar e desenvolvimento sustentável indígena (Butto, 2005). O diagnóstico foi realizado por meio de 17 oficinas, entre dezembro de 2002 e outubro de 2003, nas quais foram aplicados 322 questionários, com 415 perguntas, contemplando 194 das 235 etnias do país, situadas em 21 estados. O documento final denominou-se "Proposta de Política Nacional de Segurança Alimentar e Desenvolvimento Sustentável para os Povos Indígenas".

De acordo com Verdum (2005), as oficinas tinham como objetivo a identificação dos principais problemas e demandas dos indígenas nas diferentes regiões do país. A oficina de Mato Grosso do Sul, foi realizada, em Campo Grande, nos dias 13 a 15 de maio de 2003, contou com a participação de 27 indígenas dos povos Guarani-Kaiowá, Guató, Kadiwéu, Kinikinaua, Ofayé Xavante e Terena. Os dados coletados foram sistematizados pelo MDA - Ministério do Desenvolvimento Agrário.

De acordo com o autor supracitado, no contexto das principais aspirações em relação às etnias sul mato-grossenses, os resultados obtidos na oficina relacionados ao tema atividades produtivas e segurança alimentar se resumiram a questões como: a problemática de desgaste do

192 Simone Rodrigues Pereira CO RRÊA. Análise da implantação de políticas... 
solo em razão da qualidade ou do excesso de seu uso; o assoreamento e a poluição dos cursos d'água, reduzindo recursos pesqueiros e fontes para o consumo humano; a diminuição das florestas nativas e do espaço para implantação de roças; a redução de pescado e dos animais de caça que têm ocasionado quadros freqüentes de desnutrição infantil.

Ainda, segundo o autor, houve relatos da presença de casos de obesidade, diabetes e hipertensão nas aldeias. Para os indígenas, a entrega de "cestas básicas" apresenta alguns problemas, como a sua insuficiência, pois não atendem a todas as famílias que necessitam do benefício; a quantidade de alimentos em cada cesta nem sempre é suficiente para atender a demanda da família e a incompatibilidade de alguns alimentos com o hábito alimentar nas aldeias.

Como demanda para solucionar os problemas apresentados, os indígenas de Mato Grosso do Sul sugeriram atividades alternativas, como piscicultura, hortas caseiras e escolares, utilizadas, principalmente, na merenda escolar, além do aproveitamento de frutas excedentes na produção de doce e polpa de suco. Solicitaram, também, uma política de formação e de capacitação indígena, de aquisição de insumos, de equipamentos e de orientação técnica continuada, com o apoio técnico e financeiro de órgãos governamentais.

Quanto ao território, segundo seus relatos, o processo de regularização das terras, além de incompleto é moroso, promovendo crescente pressão sobre os poucos recursos naturais existentes nas reduzidas terras que ocupam. Destacam, ainda, problemas relacionados ao alcoolismo e ao arrendamento da pouca terra que possuem. Solicitaram, por isso, a implementação de políticas de ampliação territorial, ações de fiscalização e proteção dos territórios indígenas pelo Estado, com a participação das organizações indígenas na defesa de seus direitos constitucionais.

E, finalmente, em relação aos recursos naturais, requereram ações de valorização e proteção dos conhecimentos indígenas, especialmente sobre a biodiversidade e espécies nativas, além do incentivo à realização de programas de formação de agentes ambientais e agroflorestais indígenas, à criação de viveiros de espécies nativas e medicinais e, também, ações de saneamento e educação sanitária.

Considerando essa consulta, observa-se que, apesar do acesso a alguns serviços básicos e do fortalecimento das organizações indígenas, ainda não houve considerável melhoria nas condições de vida desse povo. Em concordância com as afirmações de Butto (2005), esse diagnóstico significa um importante passo e instrumento na elaboração de estratégias 
de atuação e intervenção de organismos indigenistas, pesquisadores, agentes públicos e movimentos sociais, caracterizando-se, nesse contexto, um grande desafio a ser enfrentado.

\section{Principais programas implantados na aldeia Limão Verde}

De acordo com os discursos dos agentes governamentais, o objetivo dos projetos de iniciativa pública é proporcionar qualidade de vida e geração de renda para que os indígenas possam tirar o sustento de suas terras, sem terem a necessidade de se assalariarem. Tal resultado, porém, nem sempre é atingido tanto na visão dos agentes quanto dos indígenas, pois, observa-se ainda, embora nem sempre muito evidente, a presença de um discurso desenvolvimentista propagado pelos agentes governamentais e que se fundamenta na perspectiva de uma produção para o mercado externo.

É importante que o processo de construção de projetos tenha a participação da comunidade a ser beneficiada de forma conjunta e efetiva, valorizando o conhecimento tradicional indígena, fundamental para o sucesso de qualquer iniciativa de desenvolvimento dessas populações. Isso pode ser alcançado reunindo os representantes indígenas e os agentes externos para juntos realizarem desde o diagnóstico e levantamento das demandas até a conclusão e avaliação dos resultados finais do trabalho.

Certamente, em decorrência, ainda, da persistência de preconceitos, alguns agentes governamentais responsáveis pela implantação de projetos de desenvolvimento local costumam atribuir e responsabilizar pela falta de sucesso dos programas os próprios indígenas que, sob sua ótica, "nem sempre são capazes de desempenhar as tarefas". No entanto, o que ocorre na maior parte das vezes, é que os Terena acabam por assumir a iniciativa e, por conta própria, encaminham os trabalhos da forma que acreditam ser a mais acertada, isto é, conforme os interesses da comunidade, adaptando o contexto do projeto para realidade socioeconômica, cultural e ambiental de sua aldeia.

Porém, ainda assim, alguns agentes não conseguem perceber a particularidade da situação nem que um projeto de desenvolvimento em comunidade indígena precisa, sobretudo, de uma análise diferenciada, ou melhor, de uma análise adequada à realidade, no caso da aldeia Limão Verde.

Para elaborar o estudo na Limão Verde foram realizadas entrevistas com representantes indígenas, além de consultas bibliográficas e documentais, buscando informações sobre os três programas governamentais,

194 Simone Rodrigues Pereira CO RRÊA. Análise da implantação de políticas... 
voltados para políticas públicas de "etnodesenvolvimento" em terras indígenas. Os programas estudados foram: o Programa de Segurança Alimentar e Nutricional, o Programa Pantanal e o Programa Tupã I.

\section{Programa de Segurança Alimentar e Nutricional}

Segundo informações da Superintendência de Programas de Inclusão Social - PIS ${ }^{5}$-, do Governo do Estado de Mato Grosso do Sul, o Programa de Segurança Alimentar e Nutricional surgiu após a constatação de que grande parte da população sul-mato-grossense vivia abaixo da "linha da pobreza", o que exigiu ações que possibilitassem a "inclusão social” dessas famílias.

Em 1999, foi assinado pelo Estado de Mato Grosso do Sul, o decreto de criação do Conselho Estadual de Segurança Alimentar Nutricional, durante a I Conferência Estadual de Segurança Alimentar Nutricional.

Em 2001, foi criado o Programa Segurança Estadual Alimentar e Nutricional $^{6}$ em que todas as famílias com crianças em idade escolar ou não e moradoras da área urbana e rural seriam beneficiadas, desde que fossem famílias abaixo da linha da pobreza.

No início do programa, todas as famílias recebiam todo mês uma cesta com 30,1 kg de alimentos. Porém, foi criado o Programa de Segurança Alimentar Cartão - PSACT, em que as famílias de áreas urbanas passaram a receber um cartão bancário para saque do benefício no valor de $\mathrm{R} \$ 100,00$ que deveriam ser gastos na compra de alimentos. Segundo a Sra. Rosanir, que foi coordenadora Municipal do PIS, em Aquidauana, até 2006, o Programa Segurança Alimentar e Nutricional havia surgido da necessidade de atender famílias que não podiam ser beneficiadas pelo Programa Bolsa Escola. O objetivo maior do Programa, segundo a informante, era oferecer uma ajuda de custo em forma de cesta básica, necessária para manter as crianças das famílias beneficiadas na escola.

Ainda segundo a ex-coordenadora, antes do programa, as famílias sobreviviam de "subempregos", pois não tinham escolha, "faziam qualquer coisa a qualquer preço". Com a alimentação garantida, o Governo acreditava que as famílias buscariam se qualificar para conseguir empregos melhores e mais dignos.

Os recursos para o programa vinham do Fundo de Investimento Social - FIS ${ }^{7}$-, do Governo Estadual de Mato Grosso do Sul. A gestão e coordenação dos programas eram de competência da Secretaria de Estado 
de Trabalho, Assistência Social e Economia Solidária - SETASS -, através da Superintendência dos Programas de Inclusão Social, assessorada pela Coordenadoria de Gestão de Programas e Coordenadoria de Apoio e Desenvolvimento de Programas.

\section{Programa Pantanal}

O Programa de Desenvolvimento Sustentável do Pantanal - Componente Especial, era um programa vinculado ao Ministério do Meio Ambiente - MMA - e depois ao Ministério do Desenvolvimento Agrário - MDA. O Programa desenvolveu um projeto denominado Atividades Sócio-Ambientais em Áreas Indígenas da Bacia do Alto Paraguai/MS. Propunha-se a promover a melhoria das condições ambientais e melhoria na qualidade de vida da população das trinta e sete comunidades indígenas da região. Centrou suas ações na implementação de melhoramentos na estrutura e serviços de saneamento ambiental e na implementação de mecanismos de apoio à sustentabilidade destas comunidades.

O objetivo geral do projeto se resumia em implementar processos sustentáveis de manejo dos recursos naturais com o incremento da produção e renda das comunidades em formas compatíveis com a tradição cultural de cada povo. Para alcançar tal empreendimento, o projeto tinha como pressuposto a adoção de um referencial analítico, sistêmico e holístico, com bases na agroecologia ${ }^{8}$ e na antropologia, para o diagnóstico e solução dos problemas, a saber:

- A compatibilização e diversificação das práticas produtivas agrícolas e extrativistas das distintas explorações com a conservação dos recursos naturais, aplicando sistemas agrosilvipastoris ${ }^{9}$, segundo um enfoque agroecológico.

- O alcance da auto-suficiência da agricultura indígena em insumos e energia externa e o não uso de agroquímicos e espécies transgênicas nas áreas indígenas, bem como a introdução criteriosa e seletiva de germoplasmas exógenos e saneamento completo das áreas indígenas.

\section{Programa Tupã I}

O Programa Tupã I ${ }^{10}$ - Programa de Apoio à Produção Auto-Sustentável das Comunidades Indígenas e Negras Rurais de Mato Grosso do Sul - foi um conjunto de projetos propostos pelo Governo do Estado, através da Secretaria de Estado de Desenvolvimento Agrário (SDA) e

196 Simone Rodrigues Pereira CO RRÊA. Análise da implantação de políticas... 
Instituto de Desenvolvimento Agrário, Assistência Técnica e Extensão Rural - IDATERRA, que seriam desenvolvidos nas comunidades para apoiá-las em seu desenvolvimento. O nome Tupã I foi uma homenagem a Marçal de Souza (Tupã I) e significa "Pequeno Deus".

De acordo com o COGEPS ${ }^{11}$ (s/a apud Pochmann, Blanes e Amorim 2006, p. 141), o programa:

[...] é um conjunto de projetos que estão sendo desenvolvidos nas áreas indígenas e nas comunidades negras situadas no meio rural, sendo algumas remanescentes de quilombos, para apoio à sustentabilidade, por meio do respeito às tradições, valorização cultural e da autonomia desses povos. Consiste em ações que vão desde emergenciais até aquelas voltadas à geração de renda do público alvo, além da estruturação de experiências que construam outra forma de organizar a agricultu$\mathrm{ra}$, baseada na agroecologia. Realiza ainda levantamentos que demonstrem o estado em que se apresentam os recursos naturais.

O objetivo do programa, segundo o IDATERRA (2004), era promover o desenvolvimento socioeconômico, com geração de renda, segurança alimentar e produção agroecológica. Tinha como princípios norteadores o olhar antropológico e o etnodesenvolvimento, respeitando e valorizando as características, a sustentabilidade e a autonomia de cada cultura.

\section{Considerações sobre os aspectos metodológicos}

A pesquisadora optou por trabalhar, nessa pesquisa, de forma qualitativa, com entrevistas semi-estruturadas. O maior problema verificado ao utilizar essa metodologia consistiu na transformação em dados quantificáveis determinados resultados da pesquisa sem perder as contribuições qualitativas, as posições críticas e os anseios do discurso do entrevistado. Porém, apesar do fator dificuldade apresentado, considerou-se que este instrumento metodológico poderia apontar de forma mais precisa os conhecimentos almejados pela pesquisa.

A presente pesquisa apresenta algumas informações de campo referentes a visitas à aldeia, em 2006. Com o encerramento dos programas naquele ano, achou-se necessário o retorno, em 2007, para levantamento de mais dados que reproduzissem também o reflexo na comunidade, por conta do corte dos programas. Essa reprodução foi possibilitada por meio das entrevistas devidamente autorizadas pelos indígenas, em que se pôde observar certa indignação dentro da comunidade. Ao mesmo tempo, porém, pôde-se perceber a capacidade de adaptação dos Terena para questões que, para eles, naquele momento, eram consideradas como adversas. 
É válido explicitar aqui que, antes das entrevistas, a pesquisadora explicava claramente os objetivos da pesquisa para os informantes para que não houvesse confusão entre os papéis de pesquisadora e agente governamental, e que não haveria influência ou qualquer prejuízo nas ações desenvolvidas como agente técnica, em decorrência de seus posicionamentos no âmbito da pesquisa. De qualquer forma, é prudente não descartar que a atuação como agente governamental pode ter influenciado, mesmo que minimamente, as respostas de alguns indígenas, devido ao receio de prejudicar programas futuros.

As entrevistas foram centralizadas em questões que identificassem os reflexos e as mudanças na organização social e política da aldeia, na economia, além de questões relacionadas à cultura Terena. Buscou-se levantar, principalmente, a opinião sobre os programas com acento no etnodesenvolvimento, a ação dos agentes, as expectativas e os reflexos dos programas desenvolvidos.

As entrevistas foram realizadas por meio de amostragem, de aproximadamente $10 \%$ do número de famílias indígenas. Foram 30 entrevistados, escolhidos, aleatoriamente, na aldeia. Devido à complexidade em se agrupar, no âmbito da pesquisa, as diferentes visões apresentadas em relação aos programas, a pesquisadora observou que, para um resultado mais claro e íntegro, seria necessária a divisão dos informantes em três grupos distintos $^{12}$ : um grupo com 10 mulheres indígenas (de 26 a 60 anos), um segundo grupo com 10 adultos indígenas do sexo masculino ( 26 a 60 anos) e um terceiro grupo com 10 jovens indígenas de ambos os sexos (entre 21 e 25 anos). O ex-cacique (2006) e o ex-chefe de posto da FUNAI (2006) também foram entrevistados para complementar a pesquisa, fornecendo informações gerais sobre a aldeia, porém, não foram incluídos em nenhum grupo.

Após a coleta foi realizada a análise, a interpretação, a organização e a correlação dos dados, que apresento a seguir.

\section{Avaliação dos programas}

Conforme apresentado anteriormente, para o desenvolvimento dessa pesquisa foi utilizada a entrevista semi-estruturada como metodologia. Buscou-se investigar como as famílias indígenas percebem a implantação das políticas públicas dentro da aldeia, assim como suas necessidades, críticas e expectativas perante o Estado. Os dados a seguir são parte da dissertação de mestrado da pesquisadora.

198 Simone Rodrigues Pereira CO RRÊA. Análise da implantação de políticas... 
Em relação aos programas desenvolvidos na aldeia, $90 \%$ da população pesquisada relatou que já foi beneficiada por eles. Esse alto número de indígenas incluídos em programas sociais confirma duas questões: primeiro, que a problemática indígena vem, aos poucos, fazendo parte dos planejamentos governamentais, o que é positivo e considerado uma conquista; e, segundo, que mesmo com a implantação de tantos projetos, nem sempre eles conseguem atingir efetivamente os objetivos propostos de aumento na geração de renda e melhoria de qualidade de vida.

A única pergunta que obteve unanimidade nas respostas, no decorrer das entrevistas, buscava saber se os programas governamentais implantados na aldeia haviam provocado redução ou mesmo o término das roças familiares. Essa era uma pergunta importante, porque havia uma percepção bastante divulgada de que esses programas, devido a seu caráter assistencialista, não só não contribuíam para o aumento da produção interna nas terras indígenas, mas eram responsáveis, inclusive, por uma redução das roças familiares. Todos os informantes responderam que não pararam de cultivar suas roças. Cabe ressaltar que, dos entrevistados, dois são aposentados, quatro funcionários públicos (dois do grupo dos adultos, um do grupo dos jovens e um do grupo das mulheres) e um é artesão, porém todos possuem um pedaço de terra onde produzem para subsistência e/ou para obtenção de renda.

De acordo com as entrevistas realizadas antes do corte dos três programas, os indígenas declararam que a comunidade, de certa forma, estaria dependente dos programas e dificilmente conseguiria sobreviver sem eles. Porém, de acordo com os relatos de 2007, após o corte dos referidos programas, percebeu-se que esse impacto ocorreu em menores proporções e nenhuma família dessa aldeia passou por "insegurança alimentar", pois, de acordo com os informantes, todos possuem sua roça e as famílias e vizinhos auxiliam famílias em condições alimentares mais precárias, não permitindo tal situação.

Outra característica constatada, além da capacidade de relativizar os impactos negativos decorrentes da instabilidade nos programas sociais, foi a grande capacidade da comunidade indígena em fazer a gestão financeira de forma autônoma. Com os relatos, a pesquisadora constatou que a sociedade envolvente ${ }^{13}$ e o Governo subestimam a capacidade indígena de administrar-se, definir suas metas e ser protagonista de seu futuro. Concluiu-se que essa comunidade está mais politizada do que se imaginava e muitas suposições, inclusive, por parte de agentes governamentais, mostraram-se não verdadeiras.

Ainda em relação à capacidade de gestão, a maior parte dos indí- 
genas considera importante os programas governamentais, pois poupam a pequena renda, em média de $\mathrm{R} \$ 100,00$ por família ${ }^{14}$, a qual seria investida em alimentação, considerada prioridade, para investir em outras demandas, tais como roupas, calçados, material escolar para os filhos e melhoria na casa.

Os programas, portanto, são bem aproveitados pelos indígenas e constituem um complemento da renda, economizando de um lado para investir no outro, segundo descreveram. Esperava-se, talvez, que a implantação desses programas governamentais fosse desorganizar suas unidades de produção e que a sua suspensão causaria transtornos e repercussões na saúde física dos indígenas, porém os relatos surpreenderam.

O relato mais interessante e que expressa bem a capacidade de gestão econômica dos indígenas foi da Sra. Audely Dias Lipú (2007):

Tive sonho de fazer banheiro, o Governo trouxe Kit Sanitário ${ }^{15}$. Demorei anos para fazer minha casa, ia demorar muito para fazer o banheiro, mas fui beneficiada. Construí minha casa a partir de programas de Governo, com o auxílio maternidade, comprei tijolos, com auxíliomédico, por ter quebrado a perna, comprei as telhas, fazendo roça comprei madeira e assim fui construindo. Se não fosse isso ia demorar muito mais.

Nessa perspectiva, fica evidente a capacidade de gestão financeira e de auto-suficiência, visto que a maioria dos entrevistados, em 2007, disseram que os programas governamentais fariam falta, muito embora pudessem sobreviver sem eles. Porém, agora teriam que trabalhar mais e a renda voltaria a ser investida apenas em alimentação.

Pensando na questão ambiental, infelizmente, a problemática do lixo ainda é muito presente na aldeia, partindo do pressuposto de que não há serviço de coleta de lixo e que os indígenas costumam armazenar os resíduos a céu aberto ou queimá-los. Apesar de não realizar um trabalho de quantificação do lixo produzido na aldeia, foi visualmente perceptível o seu acúmulo, em algumas residências, em um ano de pesquisa, principalmente, de embalagens descartáveis de produtos alimentícios provenientes tanto do Programa de Segurança Alimentar quanto adquiridos na cidade.

Os três grupos entrevistados responderam que os programas ajudaram direta e indiretamente a melhorar a situação econômica da família, sendo que as mulheres destacaram, principalmente, o Programa de Segurança Alimentar como responsável por essa melhora. Os homens, destacaram os programas direcionados à produção (Tupã I e Pantanal). Para os jovens, ambos foram importantes.

200 Simone Rodrigues Pereira CO RRÊA. Análise da implantação de políticas... 
Outro ponto de divergencia entre as respostas das mulheres e dos homens, diz respeito às expectativas de cada grupo, ficando clara a importância dada pelas mulheres ao bem estar da família, mais especificamente de seus filhos, ressaltando a relevância da segurança alimentar e, conseqüentemente, da saúde. Na visão dos homens, são mais relevantes a questão do trabalho e a geração de renda e, para os jovens, a garantia de um futuro melhor, através da educação e do emprego, seja dentro ou fora da aldeia.

A pesquisa constatou ainda que um dos principais motivos de insucesso e desencontro de projetos que se propõem ao etnodesenvolvimento na aldeia Limão Verde é o não compartilhamento, entre os Terena e os agentes governamentais, das mesmas compreensões sobre os objetivos dos programas. Um exemplo claro dessa questão foi o questionamento sobre o entendimento de cada um sobre o que é qualidade de vida, tão presente nos discursos governamentais.

Apesar de a expressão estar intimamente ligada aos conceitos de desenvolvimento humano, de bem-estar, de saúde física e mental - questões complexas e particulares -, ocorrem diferenciações nas percepções acerca do tema. Na visão do poder público, qualidade de vida está diretamente associada ao desenvolvimento econômico, pois, na fala dos agentes, para se atingir a qualidade de vida, é necessário que a comunidade "excluída" saia da "linha de pobreza", por meio do acesso à geração de renda e alcance, dessa forma, saúde, educação e segurança alimentar.

No entanto, cada grupo pesquisado possui um entendimento próprio sobre esse tema. No grupo dos homens, cerca de 50\% admitiram que qualidade de vida é sinônimo de saúde, pois alegaram que, sem saúde não teriam condições de trabalhar e que, tendo saúde, as demais realizações seriam conseqüência. Depois, 30\% dos entrevistados relacionaram qualidade de vida com o acesso ao emprego, 10\% consideram qualidade de vida como resultado do aumento da lavoura e outros $10 \%$ destacaram como fundamental o acesso à educação.

Para 60\% das mulheres, qualidade de vida remete à manutenção da saúde, para $30 \%$ tem a ver com acesso ao emprego e outros $10 \%$ relacionam à educação. Pôde-se perceber que, para as mulheres, a saúde e o emprego estavam, principalmente, relacionados à qualidade de vida dos filhos e não tanto para elas mesmas.

Para $40 \%$ dos jovens, qualidade de vida é sinônimo de saúde, para $30 \%$ relaciona-se à educação, 20\% associam ao emprego e $10 \%$ à religião. Verifica-se, portanto, uma inversão no entendimento do que é mais 
relevante para se ter qualidade de vida. Para o Governo, o aspecto mais relevante está na melhoria do poder econômico ou na geração de renda e, para os informantes indígenas, a questão central é a saúde, pois, com saúde, poderão atingir as demais demandas e melhorar seu poder aquisitivo.

Mesmo correndo-se o risco de respostas influenciadas pelo fato de a pesquisadora ser uma técnica do governo, questionou-se a atuação dos agentes técnicos. Observou-se que os índios possuem total entendimento do papel do agente na orientação técnica em atividades agrícolas dentro da aldeia.

Para tanto, questionou-se na pesquisa sobre a importância da presença de agentes governamentais na aldeia. Mais da metade das mulheres, $60 \%$, não quiseram opinar sobre esse tema, alegando que apenas o marido poderia falar sobre essa questão. Porém, $30 \%$ responderam que precisavam de orientação técnica, pois o solo estava fraco, isto é, com baixa fertilidade e $10 \%$ responderam que a comunidade precisava de orientação para plantio em época mais apropriada.

Para o grupo dos homens adultos, 50\% responderam que precisavam de orientação técnica, pois o solo estava fraco, $30 \%$ salientaram que havia a necessidade de assistência técnica no plantio para aumentar a produção, $10 \%$ entendem que é importante a presença dos técnicos do governo para auxiliar no plantio em época adequada e outros $10 \%$ para utilizarem os insumos recebidos de forma correta.

Na opinião dos jovens, os técnicos governamentais são importantes. Para $40 \%$, porque eles necessitam de orientação para a correção da terra, que está fraca, para outros $40 \%$, pela orientação sobre o plantio em época correta, em $10 \%$, para aumentar a produção e outros $10 \%$ porque precisavam de orientação sobre educação ambiental.

A média da renda auferida da comercialização dos produtos plantados na unidade de produção agrícola de cada família é de cerca de $\mathrm{R} \$$ 100,00 nos três grupos, com uma variação de $\mathrm{R} \$ 30,00$ a $\mathrm{R} \$ 150,00^{16}$. Das trinta pessoas entrevistadas, apenas seis $(20 \%)$ recebem mensalmente um salário mínimo. Esse é um número preocupante, quando relacionado ao poder de aquisição de alimentos e garantia de segurança alimentar, podendo significar que as famílias restantes, $80 \%$, estão abaixo da linha de pobreza.

De forma geral, para 50\% das mulheres, os programas em questão serviram como complemento da renda, pois puderam poupar o dinheiro que seria utilizado com alimentação para a compra de outros bens, con-

202 Simone Rodrigues Pereira CO RRÊA. Análise da implantação de políticas... 
siderados necessários, tais como: roupa, sapato, material escolar. Para $40 \%$ das mulheres, os programas foram necessários, pois não possuem condições financeiras para aquisição dos insumos para produção nas lavouras e $10 \%$ afirmaram que os programas foram insuficientes, referindo-se à quantidade de itens dos projetos e ao número de pessoas beneficiadas.

Já com o grupo dos adultos (homens), as respostas variaram muito: $20 \%$ consideraram os benefícios dos programas importantes no complemento da renda, pois possibilitava a aquisição de outros bens. Outros $20 \%$ afirmaram que precisavam dos programas, pois não possuíam condições de comprar insumos para produção. Cerca de $20 \%$ responderam que os programas eram insuficientes e preferiam programas direcionados somente ao incentivo à produção. Já $10 \%$ dos informantes preferiam empregos em vez desses programas governamentais. E, finalmente, $10 \%$ dos entrevistados alegaram que os programas eram insuficientes e deveriam ter realizado uma consulta prévia às comunidades antes da implantação. Outros $10 \%$ afirmaram que os programas são obrigação do Estado e os demais $10 \%$ disseram que não eram esses os projetos de que a comunidade necessitava, por isso consideraram essas iniciativas um desperdício ou "dinheiro jogado fora".

Na opinião dos jovens, $40 \%$ afirmaram que os programas foram importantes, pois possibilitaram a complementação da renda para a compra de outros bens. Cerca de $20 \%$ dos jovens ressaltaram que foram projetos importantes, afinal, a comunidade não possui condições financeiras para a compra de insumos para produção e 10\% dos informantes alegaram que os projetos foram importantes, visto que são "carentes" e não tinham condições financeiras para comprar alguns alimentos. Cerca de $10 \%$ dos entrevistados preferiam emprego a programas governamentais, 10\% consideravam obrigação do Estado e os demais 10\% declararam que os programas de incentivo à produção são mais eficazes que o Programa de Segurança Alimentar.

Apesar de as mulheres relatarem que em alguns casos auxiliam seus maridos no trabalho com a lavoura, $40 \%$ das mulheres entrevistadas afirmaram que essa é uma atividade de domínio masculino, sendo que, inclusive, grande parte das mulheres não se achou apta para responder a algumas questões. $\mathrm{Na}$ área de produção, a maior parte das mulheres e dos jovens não soube responder e/ou não quis opinar, por não ter informações suficientes. Na visão dos homens, as principais produções para a comercialização e subsistência foram: a mandioca, em primeiro lugar, o feijão, em segundo, o milho, em terceiro, o feijão-miúdo, em quarto, e a 
abóbora, em quinto. As demais produções, como maxixe, quiabo, entre outras, também, foram citadas em menor número.

Em relação à comercialização, apenas duas jovens entrevistadas comercializavam seus produtos em Aquidauana (feira). Do grupo dos adultos, apenas um dos entrevistados levava os produtos para comercializar na cidade. Das mulheres, $70 \%$ levavam produtos para comercializar na cidade e $30 \%$ não, por problemas de saúde, por ser servidora pública e/ou por não ter com quem deixar os filhos de menor idade. As mulheres alegaram que não fazem feira porque gostam, mas sim porque precisam ajudar a família financeiramente.

A maioria dos indígenas afirmou que a semente recebida do governo era de boa qualidade, porém alguns relataram que chegava fora da época hábil para o plantio. Muitos alegaram, também, que a quantidade de combustível recebida dos programas de incentivo à produção agrícola era insuficiente, portanto impossibilitando que o trator realizasse o preparo do solo de forma correta. Outro fator levantado foi a necessidade de mais máquinas agrícolas, pois o número de agricultores era alto e, normalmente, os últimos a serem atendidos plantavam fora de época, correndo o risco de perderem a lavoura.

Os principais problemas relativos à produção e à produtividade, na visão dos homens, foram: para 30\% deles o problema maior é a quantidade de terra disponível, considerada insuficiente, para $40 \%$, a baixa fertilidade do solo, decorrente também da excessiva exploração da pouca terra disponível. $10 \%$ das respostas indicaram como maior problema o plantio fora de época, em decorrência do atraso no preparo de solo pelo trator, que devem ser somados a outros $10 \%$ que responderam que os problemas se devem à falta de mais tratores para atender à comunidade, e, finalmente, $10 \%$ por falta de orientação técnica dos agentes governamentais.

Ainda sobre as principais dificuldades enfrentadas na aldeia, o problema principal apontado diz respeito à saúde, principalmente à falta de atendimento odontológico na aldeia. Essa foi a opinião de $50 \%$ dos jovens, $60 \%$ das mulheres e $40 \%$ dos homens adultos.

O problema de ausência de saneamento básico foi lembrado por $20 \%$ das mulheres e $10 \%$ dos jovens como principal problema. Cerca de $20 \%$ dos jovens e $10 \%$ das mulheres, tendo em vista, nesse contexto, os seus filhos, levantaram o problema do transporte para a faculdade. $40 \%$ dos adultos, $20 \%$ dos jovens e $10 \%$ das mulheres levantaram o problema da falta de emprego. $20 \%$ dos homens alegaram como problema o estado

204 Simone Rodrigues Pereira CO RRÊA. Análise da implantação de políticas... 
ruim das estradas. Outros problemas foram abordados, em menores proporções, como: individualismo, influência de políticas partidárias como fator de desunião da comunidade e problemas com a comunicação telefônica.

Pelas entrevistas, observou-se que os jovens indígenas também possuem a aspiração de concluir o nível superior, buscando, principalmente, um bom emprego, dentro ou fora da aldeia, para auxiliar a família. Paralelamente a isso, encontram-se pais que incentivam os filhos a estudarem para garantir um futuro melhor, visto que eles consideram que o trabalho na roça exige esforço físico e não é bem remunerado.

Em relação à questão da educação e do emprego fora da aldeia, $50 \%$ dos jovens pretendem sair para estudar e trabalhar fora da aldeia e $30 \%$ pretende sair para estudar e voltar para trabalhar na aldeia. Cerca de $10 \%$ dos informantes alegaram que tanto faz estudar e/ou trabalhar fora ou dentro da aldeia e os outros $10 \%$ disseram que não têm interesse em estudar e/ ou trabalhar fora.

Quanto à participação das mulheres, por unanimidade, todas responderam que possuem espaço dentro da comunidade, nas reuniões e outros eventos para opinar e que os homens nunca se opõem a essa participação. Contradizendo tal afirmativa, $20 \%$ dos homens alegaram que as mulheres não possuem espaço para opinar nas reuniões e eventos da aldeia. Todos os jovens afirmaram que as mulheres possuem o mesmo direito de opinar que os homens, porém poucas são as que fazem uso da palavra em reuniões, sendo que opinam mais em casa, com a família.

Para finalizar a pesquisa, a todos foi formulada a mesma pergunta: quais os programas que mais influenciaram na melhoria de vida na aldeia Limão Verde? Não houve diferença significativa na opinião dos diversos grupos e alguns citaram mais de um programa como importante. O Programa de Segurança Alimentar (PSA) foi considerado o mais importante por $24 \%$ dos entrevistados, o Programa Pantanal (PP) por $17 \%$ e o Programa Tupã I por $26 \%$ dos informantes ouvidos. O PSA e o PP foram considerados mais importantes na opinião de $4 \%$, o PSA e o Tupã I, na opinião de $17 \%$ e o PP e o Tupã I, na opinião de $3 \%$ das famílias. Já 7\% dos entrevistados consideraram os três programas igualmente importantes para a melhoria da qualidade de vida e $2 \%$ não opinaram sobre o assunto.

Entre as pessoas que consideraram o Programa de Segurança Alimentar como o programa que mais benefícios trouxe a sua vida, a maioria alegou que isso se deu devido ao complemento da renda mensal e 
outros por proporcionar segurança alimentar. Em relação ao Tupã I, alguns responderam que sua importância se deu porque ajudou a melhorar a produtividade na lavoura e outros porque garantiu assistência técnica até hoje. Dos que consideraram mais importante o Programa Pantanal, alguns entrevistados responderam que foi devido ao recebimento de insumos já que não teriam condições financeiras para comprá-los e outros por ter melhorado a fertilidade da terra por meio da aplicação desses insumos.

De forma geral, os indígenas entrevistados disseram que sabiam que, com a mudança de Governo, correriam o risco de não receberem mais os benefícios, mas ainda tinham esperança da continuidade dos programas.

Segundo a grande maioria dos entrevistados, os programas foram e são muito importantes, "irão fazer falta”, relatam, mas não foram considerados vitais, pois segundo os mesmos, na pior das hipóteses, o que poderá ocorrer será o aumento do trabalho nas lavouras para compensar a ausência dos benefícios. Uma outra conseqüência será a falta de condições financeiras para a compra de outros bens e insumos para produção, pois os poucos recursos serão voltados apenas para a alimentação.

\section{Considerações finais}

O estudo foi uma tentativa de identificar os impactos sócio-econômicos causados por políticas públicas, buscando mensurar a sua importância, contribuições e insucessos. É necessário um adendo, uma vez que faz parte do senso comum acreditar na incapacidade das sociedades indígenas para gerir seus territórios. Parte-se do pressuposto de um quadro de desorganização das unidades de produção indígena, de queda de produção e dependência total dos benefícios provenientes de programas governamentais.

No entanto, apesar da constatação de falhas, antes e durante a implantação desses programas, os resultados foram surpreendentes. Primeiro, os programas estudados foram "bemvindos", assim como muitos outros, pois os beneficiários índios demonstraram que necessitam de programas sociais, mesmo que eles apresentem crônicas limitações. É relevante a constatação sobre a capacidade de os indígenas redirecionarem, estrategicamente esses aportes externos e, dessa forma, suprirem suas necessidades básicas. Ou, em outros termos, os representantes indígenas ouvidos pela pesquisa mostraram surpreendente clareza no sentido de

206 Simone Rodrigues Pereira CO RRÊA. Análise da implantação de políticas... 
direcionar os recursos para as suas demandas mais relevantes.

A pesquisa confirmou ainda a grande capacidade dos indígenas para gerir e administrar recursos e benefícios decorrentes desses programas, transformando-os em complemento da pequena renda auferida, proveniente da agricultura. Os índios não pararam de plantar em decorrência desses programas, conforme atestam $100 \%$ (cem por cento) das respostas e muito menos passaram por um processo de "insegurança alimentar", após o corte dos recursos.

Falar em autonomia de um povo perante o estado e a seus programas sociais, num contexto de pobreza torna-se utópico. Por outro lado, não é possível falar em total dependência, no caso da aldeia de Limão Verde, como vem afirmado em vários estudos. Em decorrência de sua proximidade e experiência adquirida no processo de interação com a sociedade não indígena e sua experiência histórica de povo agricultor, mostram interessante capacidade de se adaptar a novas situações e a superar adversidades a que foram e são continuamente submetidos.

Pôde-se observar e confirmar, por meio das respostas dos entrevistados, que buscam no Estado políticas públicas que contribuam com sua auto-suficiência sem caracterizar dependência dos referidos programas.

Não obstante a persistência dos impasses relativos ao acesso às suas terras em decorrência do processo engessado de regularização fundiária e de aumento da pressão ambiental, os índios de Limão Verde alcançaram avanços em relação a alguns serviços básicos. No entanto, cabe destacar que, sem a superação dos problemas relativos à ampliação das terras, somada ao aumento populacional, a tendência será de crescente queda na sua qualidade de vida, que de acordo com as respostas dos grupos, é sinônimo de acesso e manutenção da saúde.

Constatou-se, através da pesquisa, que o etnodesenvolvimento depende de vontade política, porque exige que o poder público rompa com o sistema assistencialista implantado e passe do discurso sobre para a efetiva construção de políticas públicas, de acordo com as aspirações do público-alvo, no caso, os povos indígenas. A busca pela implantação de sistemas agropecuários sustentáveis se deu após estudos demonstrarem que o modelo convencional, baseado no uso dos recursos naturais, de agroquímicos e maquinários agrícolas, permite o aumento da produção e da produtividade e causa, porém, em quase todos os casos, a degradação do meio ambiente.

Entretanto, como aumentar ou manter a produtividade atual, que garanta a subsistência e a geração de renda necessária à vida da 
população indígena através de técnicas menos prejudiciais e mais sustentáveis, mas que requerem um espaço de tempo mais longo para gerarem respostas? São questões que devem ser analisadas, previamente, para a elaboração de futuros programas. Em decorrência do confinamento territorial, os Terena enfrentam hoje desafios contraditórios. Povos com uma longa e singular experiência de inserção regional, sem provocar maiores danos ao ambiente local, confrontam-se hoje com a necessidade de projetos de recuperação ambiental e demandam recursos do Estado para esse fim.

Ao serem confinados em reduzidas terras que, inclusive, não previam o aumento demográfico, a pressão sobre os recursos naturais vem aumentando. E erra, novamente, o Estado por não enfrentar, propositalmente ou não, essa questão de fundo, que diz respeito à necessária ampliação das terras. No entanto, apesar das críticas, os Terena admitiram a necessidade de políticas públicas para melhorar a qualidade de vida.

O desafio está lançado e, para superar os impasses encontrados, será fundamental a garantia de um verdadeiro diálogo. Afinal, se o desenvolvimento, na sua dimensão clássica de atendimento ao não indígena, não tem atingido as expectativas, o problema agrava-se mais ao tratar de sociedades indígenas.

Nesse contexto espera-se que os resultados da pesquisa realizada possam contribuir para situar o Estado em relação à importância de seu papel perante as demandas das comunidades indígenas e que os sucessos e insucessos apresentados contribuam para um verdadeiro "etnodesenvolvimento".

\section{Notas}

levado um longo período para início de seu reconhecimento como "reserva indígena", foi um processo realizado de forma diferenciada das demais aldeias, na aquisição dos 1.238 ha e 1.789,97 m² (Lei n. 650/72). A compra de 512 ha e $1900 \mathrm{~m}^{2}$ (matrícula 349/R de 1978). E os 2.913 hectares que foram adquiridos pela FUNAI. Após um estudo, em 1997, pela FUNAI, para analisar os 2.913 hectares reivindicados pelos indígenas - 31 imóveis incidentes-, a área total da Terra Indígena Limão Verde somaria 4.886 hectares. Essa área foi demarcada, homologada, contudo, nem toda, ainda, incorporada, por diversas razões, tais como: falta de pagamento ou desentendimento dos posseiros quanto ao valor da indenização a ser paga.

${ }^{2}$ Paulatinamente propostos em todos os níveis da sociedade.

${ }^{3}$ Mesmo que ainda mais nos discursos do que em ações e mais na concepção

208 Simone Rodrigues Pereira CO RRÊA. Análise da implantação de políticas... 
tecnocrática do marco conceitual do que na aspiração indígena.

${ }^{4}$ Que começou no governo de Fernando Henrique Cardoso e foi remodelado no governo Lula, quando foi formado, em 2002, um grupo intergovernamental (sob coordenação do MDA - Ministério do Desenvolvimento Agrário).

${ }^{5}$ De acordo com o COGEPS [S/d] apud Pochmann, Blanes e Amorim (2006), o PIS foi criado para "atendimento a cerca de 80 mil famílias, entre indígenas, quilombolas, acampadas, populações rurais e urbanas, em duas modalidades de atendimento: Bolsa Escola (20 mil famílias), Segurança Alimentar (60 mil famílias), além do Bolsa Família (2.260 mil famílias), em parceria com o governo federal". Ver mais em Pochmann, Blanes e Amorim (2006).

${ }^{6}$ As normas sobre o Programa de Segurança Alimentar e Nutricional são apresentadas, detalhadamente, em dois decretos, o de n. 10.244, de 8 de fevereiro de 2001, que instituiu o programa e o den. 11.587, de 20 de abril, de 2004, em que o Programa de Inclusão Social foi criado.

${ }^{7}$ Fundo criado no ano de 2000, exclusivamente para ações na área social (combate à pobreza e exclusão social), através da Lei Estadual n. 2.105. Constituido como receitas, contribuições de empresas interessadas no programa, transferências à conta do Orçamento Geral do Estado, contribuições de entidades públicas, privadas, nacionais ou estrangeiras, juros, correções e rendimentos bancários, doações, legados e qualquer renda a ele destinado. Ver mais em Pochmann, Blanes e Amorim (2006). ${ }^{8}$ De acordo com Assis e Jesus (2005, p. 39): “A agroecologia é a ciência que procura estabelecer uma base teórica para esta agricultura não industrial, procurando entender o funcionamento do agroecossistema e preservar e ampliar a sua biodiversidade, para produzir auto-regulação e sustentabilidade. A ciência agroecológica tem por objetivo o estabelecimento de agroecossistemas sustentáveis. Para a consecução deste desafio, a agroecologia procura compreender o funcionamento e a natureza dessas unidades, integrando, para isso, princípios ecológicos e agronômicos, bem como socioeconômicos, na medida que observa os agroecossistemas como unidades estabelecidas pelo homem".

${ }^{9}$ Segundo Assis et al. (2005, p. 117), "são sistemas que integram produção agrícola e/ou pecuária com a produção de produtos florestais".

${ }^{10}$ Foi instituído pelo Decreto n. 11.492, de 03 de dezembro de 2003.

${ }^{11}$ Conselho de Gestão Estadual de Políticas Sociais (COGEPS), composto por 18 membros, 11 secretários e o procurador-geral do estado, além de 6 membros nomeados pelo governador sem vínculo com o executivo. Criado pelo Decreto Estadual 9.825, de 25 de fevereiro de 2000, para gerir a implementação de políticas sociais no estado. Ver mais em Pochmann, Blanes e Amorim, 2006.

${ }^{12}$ A classificação (idade) dos grupos foi definida pela pesquisadora, de acordo com a idade dos entrevistados.

${ }^{13}$ Essa expressão refere-se aos não-índios que vivem no entorno das terras indígenas e com os quais os moradores da aldeia Limão mantêm fortes relações.

${ }^{14}$ Considerando a renda da família dos entrevistados e dos que responderam ao questionário.

${ }^{15}$ Programa da FUNASA de Saneamento em Terras Indígenas por meio de constru- 
ção de banheiros (pia, vaso sanitário e fossa séptica).

${ }^{16}$ Baseado no salário mínimo de R \$350,00.

\section{Referências}

ASSIS, Renato Linhares de et al. A Conversão de Sistemas Convencionais para Sistemas Orgânicos de Produção no Brasil. In: PADOVAN, Milton Parron et al. Agroecologia em Mato Grosso do Sul: princípios, fundamentos e experiências. Dourados: EMBRAPA Agropecuária Oeste, 2005.

ASSIS, Renato Linhares de; JESUS, Eli Lino de. Histórico, Conceitos e Princípios da Agroecologia. In: PADOVAN, Milton Parron et al. Agroecologia em Mato Grosso do Sul: princípios, fundamentos e experiências. Dourados: EMBRAPA Agropecuária Oeste, 2005.

AZANHA, Gilberto. Etnodesenvolvimento, mercado e mecanismos de fomento: as possibilidades de desenvolvimento sustentado para sociedades indígenas no Brasil. In: SOUZA LIMA, Antônio Carlos de; HOFFMANN, Maria Barroso (Orgs.). Etnodesenvolvimento e Políticas Públicas: bases para uma nova política indígenista. Rio de Janeiro: LACED, 2002.

BRAND, Antônio. Desenvolvimento local em comunidades indígenas no Mato Grosso do Sul: a construção de alternativas. Interações, Campo Grande, v. 1, n. 2, mar. 2001.

BRASIL. Constituição (1988). Constituição da República Federativa do Brasil.

Estatuto do Índio, Lei n. 6.001 de 19 de Dezembro de 1973. Brasília. Publicado no Diário Oficial de 21 de Dezembro de 1973.

Ministério do Desenvolvimento. Decreto n. 10.244, de 08 de fevereiro de 2001. Dispõe sobre a instituição do Programa Segurança Alimentar e Nutricional e dá outras providências.

Ministério da Agricultura, Pecuária e Abastecimento. Decreto n. 11.492, de 03 de dezembro de 2003. Dispõe sobre a instituição do Programa de Apoio à Produção Auto-Sustentável das Comunidades Rurais Indígenas e Negras de Mato Grosso do Sul - Tupã I.

Ministério do Desenvolvimento. Decreto n. 11.587, de 20 de abril de 2004. Dispões sobre a criação do Programa de Inclusão Social e dá outras providências.

Conselho Nacional de Segurança Alimentar e Nutricional - CONSEA. $O$ que é Segurança Alimentar e Nutricional. Disponível em: <http:/ /www.planalto. gov.br/consea/static/apresenta/seguranca.htm>. Acesso em: 29 mar. 2007.

BUTTO, Andrea. Segurança Alimentar indígena em dados. In: VERDUM, Ricardo (Org.). Assistência Técnica e Financeira para o Desenvolvimento Indígena: possibilidades e desafios para políticas públicas. Rio de Janeiro: Contra Capa/Brasília: NEAD, 2005.

FEHLAUER, Tércio. “Conhecimento Indígena” em perspectiva: performance, habilidades e capacidades agrícolas dos Terena da aldeia Limão Verde (Aquidauana/

210 Simone Rodrigues Pereira CO RRÊA. Análise da implantação de políticas... 
MS). Dissertação (Mestrado em Agroecossitemas) - PGA/UFSC, Florianópolis, 2004. FUNAI - Fundação Nacinal do Índio. Relatório de Identificação e Delimitação da Terra Indígena Limão Verde, Aquidauana/MS. GT. Port. N. 1180/PRES de13/12/ 96 e 018/PRES de 10/1/97.

FUNASA - Fundação Nacional de Saúde. Resumo geral, pólo base: AquidauanaMS, 2007.

IDATERRA, Instituto de Desenvolvimento Agrário, Assistência Técnica e Extensão Rural de Mato Grosso do Sul. Escritório Municipal de Aquidauana/MS, 2004.

MATO GROSSO DO SUL (Estado). Decreto Estadual n. 9.825, de 25 de fevereiro de 2000. Dispõe sobre a criação do Conselho de Gestão Estadual das Políticas Sociais e dá outras providências.

POCHMANN, Marcio; BLANES, Denise; AMORIM, Ricardo (Coords.). Inclusão social: uma utopia possível. Impacto das políticas públicas de Mato Grosso do Sul. São Paulo: Cortez, 2006.

PROGRAMA PANTANAL - Componente Especial. Projeto de Atividades SócioAmbientais em Áreas Indígenas da Bacia do Alto Paraguai do Estado de Mato Grosso do Sul. Ministério do Meio Ambiente e Governo do Estado de MS. Campo Grande: [s.n.], 2002.

VERDUM, Ricardo (Org.). Assistência técnica e financeira para o desenvolvimento indígena: possibilidades e desafios para políticas públicas. Rio de Janeiro: Contra Capa/Brasília: NEAD, 2005.

Recebido em 16 de fevereiro de 2008.

Aprovado para publicação em 12 de março de 2008. 
